Check for updates

Cite this: RSC Adv., 2019, 9, 9629

Received 25th February 2019

Accepted 20th March 2019

DOI: 10.1039/c9ra01430f

rsc.li/rsc-advances

\section{Characterization of biosurfactant lipopeptide and its performance evaluation for oil-spill remediation $\uparrow$}

\author{
Jun-Qiao Feng, (D) ${ }^{a}$ Hong-Ze Gang, ${ }^{a}$ Dong-Sheng Li, ${ }^{a}$ Jin-Feng Liu, ${ }^{a}$ \\ Shi-Zhong Yang ${ }^{a}$ and Bo-Zhong Mu (D)*ab
}

Biosurfactant lipopeptide is a promising dispersant over varieties of chemical ones in oil-spill remediation. The toxicity, biodegradability and performance of the biosurfactant lipopeptide are studied in this paper.
Dispersants were globally applied to physico-chemically enhance the dispersion of oil in water and were assumed to stimulate oil biodegradation by indigenous microorganisms and to reduce the environmental impact of oil spills..$^{1,2}$ Since the $1960 \mathrm{~s},{ }^{3,4}$ chemical dispersants have been applied as an emergency response to oil spills in marine ecosystems, ${ }^{5}$ and have showed effectiveness at removing oil slicks from the coast. ${ }^{3,6,7}$ However, most of the chemically synthesized dispersants are inherently toxic to various aquatic species and hardly biodegradable in the natural environment. ${ }^{2,8}$ The application of chemical dispersants in the 2010 Gulf of Mexico oil spill also raised concerns regarding the toxicity and the potential environmental impact, ${ }^{9,10}$ and caused a debate about the effectiveness of chemical dispersants on the rates of oil biodegradation. ${ }^{11}$ Biosurfactants are promising dispersants in oil-spill remediation, owning to their environmentally friendly and biodegradable properties. ${ }^{12}$ Chemical surfactants could be replaced with biosurfactants and this change would diminish the environmental impact of traditional dispersants. ${ }^{8,13,14}$ Lipopeptide produced by microorganisms is one of the representative biosurfactants and has showed great potential applications in food, ${ }^{15}$ medicine, ${ }^{16}$ microbial enhanced oil recovery, ${ }^{17}$ and other fields. ${ }^{18}$ Nevertheless, the knowledge about the application of biosurfactant lipopeptide in marine oil-spill remediation is still limited.

In the present work, the dispersion effectiveness, aquatic toxicity, biodegradability and environmental compatibility of the biosurfactant lipopeptide were determined using recognized standardized methods, ${ }^{19-23}$ and the biosurfactant

${ }^{a}$ State Key Laboratory of Bioreactor Engineering, School of Chemistry and Molecular Engineering, East China University of Science and Technology, Shanghai 200237, P. R. China. E-mail: bzmu@ecust.edu.cn; Fax: +86 21 64252485; Tel: +86 2164252063 ${ }^{b}$ Engineering Research Center of Microbial Enhanced Oil Recovery, East China University of Science and Technology, 130 Meilong Road, Shanghai 200237, P. R. China

$\dagger$ Electronic supplementary information (ESI) available. See DOI: 10.1039/c9ra01430f lipopeptide used as a bio-dispersant for marine oil-spill remediation were studied, which is, to the best of our knowledge, the first report about biosurfactant lipopeptide used in oil-spill remediation.

The lipopeptide samples were isolated from cell-free broth of B. subtilis HSO121 at our laboratory. ${ }^{24}$ The typical chemical structure of the lipopeptide used in the study was shown in Fig. 1 and its critical micelle concentration (CMC) was $8.69 \times$ $10^{-5} \mathrm{~mol} \mathrm{~L}^{-1}$.

Dispersion effectiveness (DE) of lipopeptides was examined at different surfactant-to-oil ratios (SORs), temperatures, $\mathrm{pH}$ values, and salinities. It indicated in Fig. 2 that DE of lipopeptides reached $70.23 \%$ at SORs of $1: 10(\mathrm{w} / \mathrm{w})$ at $25^{\circ} \mathrm{C}, \mathrm{pH} 7$ and the present of $3 \% \mathrm{NaCl}(\mathrm{w} / \mathrm{v})$. It should be noticed that the DE of lipopeptides was almost kept when SORs dropped to $1: 250 \mathrm{w} / \mathrm{w}$. The increase in DE with increasing SORs can be attributed to the generation of emulsions with smaller droplets and lower rising velocity. ${ }^{2}$ Sharp drop off in DE was observed for lipopeptides when SORs below $1: 500(\mathrm{w} / \mathrm{w})$, and DE value was $36.45 \%$ at an extreme SORs of $1: 1250(\mathrm{w} / \mathrm{w})$. It had been reported that the abrupt decline for $80: 20$ lecithin : Tween $80(\mathrm{w} /$ w) surfactant happened when SORs below $1: 100 \mathrm{v} / \mathrm{v}$, from $77 \%$ (SORs $1: 100 \mathrm{v} / \mathrm{v}$ ) to $15 \%$ (SORs $1: 200 \mathrm{v} / \mathrm{v}$ ), ${ }^{25}$ indicating a lower

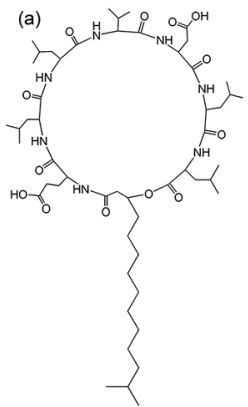

(b)

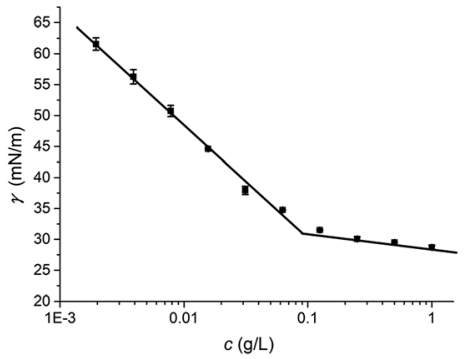

Fig. 1 Typical chemical structure of lipopeptides (a) and the surface tensions of lipopeptides respect to concentrations (b). 


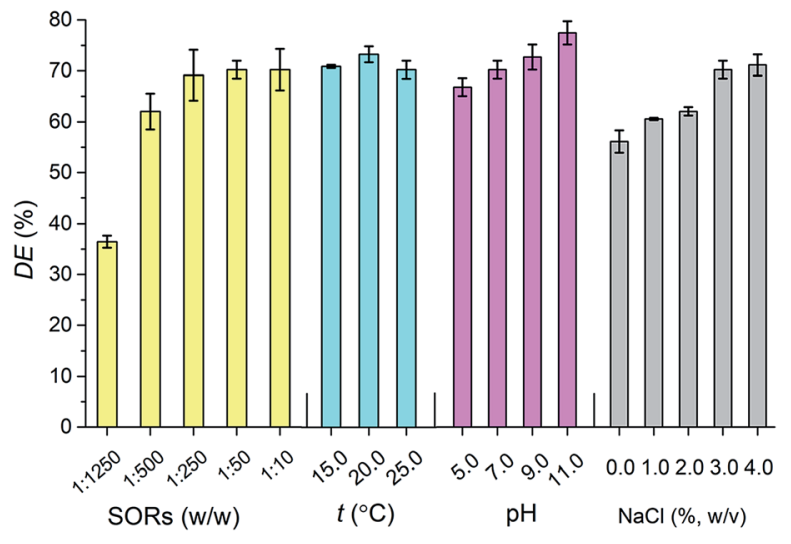

Fig. 2 The dispersion effectiveness (DE) of lipopeptides under different SORs $(\square)$, temperatures $(\square)$, pH values $(\square)$ and salinities $(\square)$.

SOR in lipopeptides usage could reach its maximum effectiveness. Lipopeptides exhibited $>70 \% \mathrm{DE}$ values with temperatures ranged from $15{ }^{\circ} \mathrm{C}$ to $25^{\circ} \mathrm{C}$, and an increasing DE values when $\mathrm{pH}$ values raised, the largest $\mathrm{DE}$ was $77.45 \%$ at $\mathrm{pH} 11$. DE of lipopeptides increased from $56.12 \%$ to $71.14 \%$ with increase in salinity. Higher DE at higher salinity was observed for anionic biosurfactants, which can be attributed to the electrostatic repulsion between polar head groups reduced by ions, and a close-packed arrangement of surfactant molecules at the oilwater interface were formed. ${ }^{2}$

Mortalities of zebrafish under different concentrations of different surfactants were shown in Fig. 3. It was evident that the toxicity of lipopeptides was far less than those of sodium dodecyl sulfate (SDS) and 3-(N,N-dimethyl palmityl ammonio) propane sulfonate (Betaine). The $24 \mathrm{~h}$ median lethal concentration $\left(\mathrm{LC}_{50}\right)$ values were calculated and showed in Table 1 . The $24 \mathrm{~h} \mathrm{LC}_{50}$ values of lipopeptides, SDS, and Betaine for zebrafish were $1145 \mathrm{mg} \mathrm{L}^{-1}, 8.25 \mathrm{mg} \mathrm{L}^{-1}$, and $0.872 \mathrm{mg} \mathrm{L}^{-1}$, respectively. The toxicity of SDS was comparable to the study by Edwards et al. ${ }^{26}$ in which an $96 \mathrm{~h} \mathrm{LC}_{50}$ of $1.9 \mathrm{mg} \mathrm{L}^{-1}$ for Cyprinodon variegatus was reported. Low toxicities of lipopeptides on whiteleg shrimp and copepods were also evaluated that the $96 \mathrm{~h}$ $\mathrm{LC}_{50}$ of lipopeptides from Bacillus sp. GY19 were $1050 \mathrm{mg} \mathrm{L}^{-1}$ and $1174 \mathrm{mg} \mathrm{L}^{-1}$, respectively. ${ }^{27}$

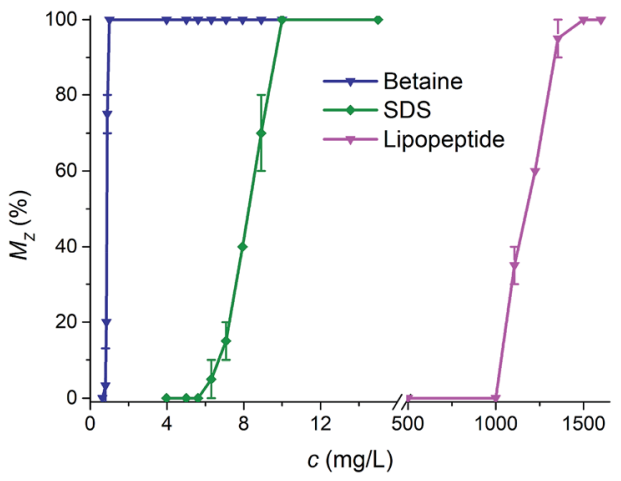

Fig. 3 Mortality of zebrafish $\left(M_{z}\right)$ after a 24 h exposure to Betaine, SDS or lipopeptides.
Table 1 Ecotoxicity of tested surfactants to the zebrafish

\begin{tabular}{llll}
\hline Surfactant & $\mathrm{LC}_{50}\left(\mathrm{mg} \mathrm{L}^{-1}\right)$ & $\begin{array}{l}\text { 95\% confidence } \\
\text { intervals }\left(\mathrm{mg} \mathrm{L}^{-1}\right)\end{array}$ & $r$ \\
\hline Lipopeptide & 1145 & $1090-1229$ & 0.981 \\
SDS & 8.25 & $7.75-8.77$ & 0.998 \\
Betaine & 0.872 & $0.853-0.890$ & 0.988
\end{tabular}

Fig. 4 illustrated the evolution of Pseudokirchneriella subcapitata concentrations in the algal growth inhibition test of lipopeptides and SDS. Growth rates of P. subcapitata were decreased with the increase of surfactant concentrations. $72 \mathrm{~h}$ median effect concentration $\left(\mathrm{EC}_{50}\right)$ values were calculated using linear regression analysis based on the dose-response curves, ${ }^{28}$ and the $72 \mathrm{~h} \mathrm{EC}_{50}$ value of lipopeptide was $1703 \mathrm{mg} \mathrm{L}^{-1}$, which was about 45 times higher than that of SDS, $36.51 \mathrm{mg} \mathrm{L}^{-1}$. $\mathrm{EC}_{50}$ was in well accordance with $\mathrm{LC}_{50}$ mentioned above, indicating that lipopeptides showed a much lower toxicity than that of SDS. The $72 \mathrm{~h}$ median inhibitory concentration $\left(\mathrm{IC}_{50}\right.$, equivalent to $\mathrm{EC}_{50}$ ) of SDS on Raphidocelis subcapitata was $36.58 \mathrm{mg} \mathrm{L}^{-1},{ }^{29}$ which was relatively close to the result in this work. However, De Oliveira et al. ${ }^{28}$ showed that the $\mathrm{EC}_{50}$ of crude surfactin on Selenastrum capricornutum (named as well as P. subcapitata) from B. subtilis ICA56 was $49.3 \mathrm{mg} \mathrm{L}^{-1}$. The lower toxicity of lipopeptides in our study was probably because the lipopeptides from various Bacillus sp. strains might have different activity. ${ }^{27}$ The $\mathrm{EC}_{50}$ values for 9 types of surfactants including anionic surfactants, nonionic surfactants, and zwitterionic surfactants on P. subcapitata were range from 1.5 to $4.4 \mathrm{mg} \mathrm{L}^{-1} .^{30}$ Hence, according to data mentioned, lipopeptides from HSO121 in the present showed less toxicity.

Biodegradabilities of lipopeptides and sodium dodecyl benzene sulfonate (SDBS) versus time were shown in Fig. 5 . With the same initial concentrations, $30 \mathrm{mg} \mathrm{L}^{-1}$, biodegradability values of biosurfactant lipopeptides and the synthetic surfactant SDS after 7 days incubation were $100 \%$ and $98.83 \%$, respectively. Lipopeptides degraded much faster than SDBS that the degradability was nearly $100 \%$ after 3 days. Biodegradability of lipopeptides by P. putida CECT 324 strain, around $82 \%$ after 3 days, was reported, which was higher than that of amine

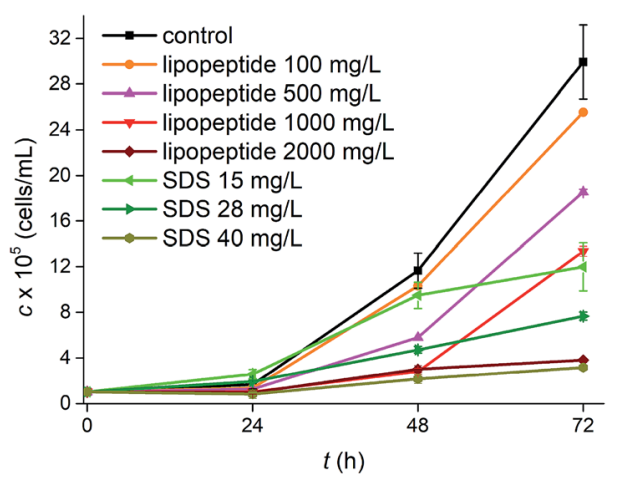

Fig. 4 Effect of lipopeptides and SDS on growth concentrations (c) of Pseudokirchneriella subcapitata during 72 hours of incubation. 


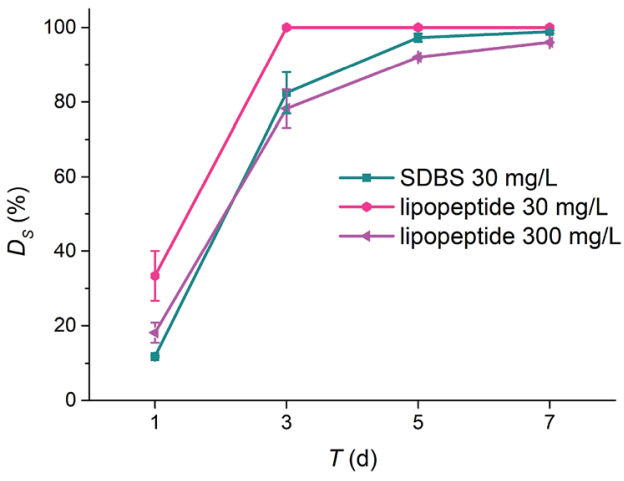

Fig. 5 Degradation of surfactants $\left(D_{S}\right)$ including lipopeptides and SDBS during $7 \mathrm{~d}$ test in activated sludge systems.

oxides. $^{29}$ Lipopeptides showed higher biodegradability as $94.01 \%$ even increasing the initial concentration to $300 \mathrm{mg} \mathrm{L}^{-1}$. Lima et al. ${ }^{31}$ studied the biodegradability of surfactants and observed the lowest decrease $(24.8 \%)$ in SDS, the highest decrease in lipopeptides (69.1\%) and glycolipid (73.4\%). Biosurfactants were seemed to be more biodegradable than synthetic surfactants.

The degradation rates of aliphatic fractions $\left(n-\mathrm{C}_{11}-\mathrm{C}_{29}\right)$ in crude oil (Xinjiang oilfield, P. R. China) were analysis using GCMS and the results were illustrated in Fig. 6. Significant
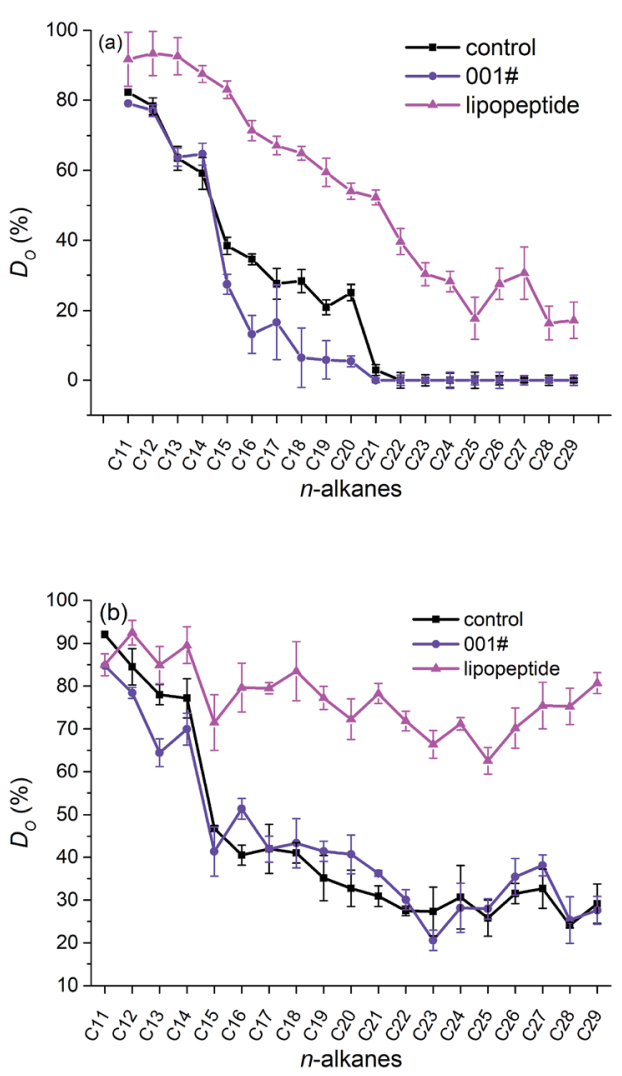

Fig. 6 Degradation of $n$-alkanes in crude oil $\left(D_{\circ}\right)$ either non-dispersed (control) or dispersed by commercial dispersant (001\#) and lipopeptides at day 1 (a), day 2 (b). degradation rates of $n$-alkanes were observed in presence of biosurfactant lipopeptides, while $n$-alkanes dispersed by commercial dispersant degraded similar to that in control group (in absence of any surfactant). It was well known that the degradation rates of alkanes decreased and finally vanished with increase in the chain length of hydrocarbon. In the present study, lipopeptides showed excellent activity in accelerating degradation of long-chain hydrocarbons after 2 days. The alkanes degradation rates treated by lipopeptides after 1 day and 2 days were $38.78 \%$ (Fig. 6a) and $71.45 \%$ (Fig. 6b), respectively, which were much higher than those of commercial dispersant-treated group (9.16\% and $34.16 \%$ after 1 day and 2 days treatment) and control group (13.26\% and $33.55 \%$ after 1 day and 2 days treatment). It was reported that commercial chemical dispersants such as Corexit 9500A and GM-2 made no enhancement to the degradation of the petroleum hydrocarbons, whereas biosurfactants such as rhamnolipids enhanced the degradation. ${ }^{32,33}$ Degradation stimulation by lipopeptides could be attributed to their good dispersion activities and biocompatible. Dispersed oil droplets formed and considerable interfacial area was available to the microorganisms followed by microbial bioremediation. In addition, microorganisms could utilize the nutrients derived from culture broth as an excellent substrate for growth. ${ }^{34}$

\section{Conclusions}

In the present study, lipopeptides secreted by Bacillus subtilis HSO121 showed good dispersion effectiveness on crude oil (Xinjiang oilfield, P. R. China) at low SOR and kept this activity against temperature, $\mathrm{pH}$ values, and salinity. Comparing with SDS and Betaine, lipopeptides exhibited much lower toxicity, significant biocompatible, and higher activity in stimulating in microbial biodegradation of crude oil. In conclusion, lipopeptides acted effectively at dispersing oil and performed excellently at stimulating microbial oil biodegradation, which indicated its application in oil spill cleaning.

\section{Conflicts of interest}

There are no conflicts of interest to declare.

\section{Acknowledgements}

This research was supported by the National High Technology Research and Development Program of China (2013AA064403), the Fundamental Research Funds for the Central Universities of China (222201717017, 22221818014), and Research Program of State Key Laboratory of Bioreactor Engineering.

\section{Notes and references}

1 S. Kleindienst, J. H. Paul and S. B. Joye, Nat. Rev. Microbiol., 2015, 13, 388-396.

2 E. Nyankson, M. J. DeCuir and R. B. Gupta, ACS Sustainable Chem. Eng., 2015, 3, 920-931. 
3 R. R. Lessard and G. Demarco, Spill Sci. Technol. Bull., 2000, 6, 59-68.

4 EMSA, Manual on the applicability of oil spill dispersants, version 2, 2009.

5 O. G. Brakstad, T. R. Storseth, A. Brunsvik, K. Bonaunet and L. G. Faksness, Chemosphere, 2018, 204, 290-293.

6 H. Chapman, K. Purnell, R. J. Law and M. F. Kirby, Mar. Pollut. Bull., 2007, 54, 827-838.

7 L. S. Stoermer and L. G. Butler, International Oil Spill Conference, Tampa, Florida, 2001.

8 R. S. Makkar and S. S. Cameotra, Appl. Microbiol. Biotechnol., 2002, 58, 428-434.

9 R. Almeda, C. Hyatt and E. J. Buskey, Ecotoxicol. Environ. Saf., 2014, 106, 76-85.

10 R. C. Prince, Environ. Sci. Technol., 2015, 49, 6376-6384.

11 S. M. Techtmann, M. B. Zhuang, P. Campo, E. Holder, M. Elk, T. C. Hazen, R. Conmy and J. W. S. Domingo, Appl. Microbiol. Biotechnol., 2017, 83, e03462-16.

12 H. Y. Gong, Y. M. Li, M. T. Bao, D. Lv and Z. N. Wang, RSC Adv., 2015, 5, 37640-37647.

13 R. Marchant and I. M. Banat, Biotechnol. Lett., 2012, 34, 1597-1605.

14 E. Nyankson, D. Rodene and R. B. Gupta, Water, Air, Soil Pollut., 2015, 227, 29.

15 G. S. Kiran, S. Priyadharsini, A. Sajayan, G. B. Priyadharsini, N. Poulose and J. Selvin, Front. Microbiol., 2017, 8, 1138.

16 F. Rivardo, R. J. Turner, G. Allegrone, H. Ceri and M. G. Martinotti, Appl. Microbiol. Biotechnol., 2009, 83, 541-553.

17 T. de Sousa and S. Bhosle, Bioresour. Technol., 2012, 123, 256-262.

18 I. Mnif and D. Ghribi, Biopolymers, 2015, 104, 129-147.

19 OECD, OECD guidelines for testing of chemicals: algal growth inhibition test, test guideline no. 201, 1984.
20 ISO, Water quality - determination of the acute lethal toxicity of substances to a freshwater fish, 1996, ISO 7346-7341.

21 SBQTS, Test method for biodegradability of surfactants, GB 15818-12006, 2006.

22 SBQTS, Oil Spill Dispersant-Technical Regulations, GB 18188.18181-12000, 2000.

23 EPA, EPA NCP Product Schedule 40 CFR Part 300, 1996, appendix C.

24 X. Y. Liu, S. Z. Yang and B. Z. Mu, J. Pept. Sci., 2008, 14, 864875.

25 D. A. Riehm, J. E. Neilsen, G. D. Bothun, V. T. John, S. R. Raghavan and A. V. McCormick, Mar. Pollut. Bull., 2015, 101, 92-97.

26 K. R. Edwards, J. E. Lepo and M. A. Lewis, Mar. Pollut. Bull., 2003, 46, 1309-1316.

27 W. Rongsayamanont, S. Soonglerdsongpha, N. Khondee, O. Pinyakong, C. Tongcumpou, D. A. Sabatini and E. Luepromchai, J. Hazard. Mater., 2017, 334, 168-177.

28 D. W. De Oliveira, A. B. Cara, M. Lechuga-Villena, M. GarciaRoman, V. M. Melo, L. R. Goncalves and D. A. Vaz, J. Environ. Sci. Health, Part A: Toxic/Hazard. Subst. Environ. Eng., 2017, 52, 174-181.

29 E. Liwarska-Bizukojc, K. Miksch, A. Malachowska-Jutsz and J. Kalka, Chemosphere, 2005, 58, 1249-1253.

30 Z. Pavlic, Z. Vidakovic-Cifrek and D. Puntaric, Chemosphere, 2005, 61, 1061-1068.

31 T. M. S. Lima, L. C. Procópio, F. D. Brandão, A. M. X. Carvalho, M. R. Tótola and A. C. Borges, Biodegradation, 2011, 22, 585-592.

32 Y. R. Pi, M. T. Bao, Y. Q. Liu, T. Y. Lu and R. He, J. Cleaner Prod., 2017, 153, 74-82.

33 Y. R. Pi, B. Chen, M. T. Bao, F. Q. Fan, Q. H. Cai, L. Ze and B. Y. Zhang, Bioresour. Technol., 2017, 232, 263-269.

34 H. Saeki, M. Sasaki, K. Komatsu, A. Miura and H. Matsuda, Bioresour. Technol., 2009, 100, 572-577. 